\title{
Characterisation of vitamin and mineral supplement users differentiated according to their motives for using supplements: results of the German National Nutrition Monitoring (NEMONIT)
}

\author{
Anne Frey, Ingrid Hoffmann and Thorsten Hever* \\ Department of Nutritional Behaviour, Max Rubner-Institut, Federal Research Institute of Nutrition and Food, Haid-und- \\ Neu-Strasse 9, 76131 Karlsruhe, Germany
}

Submitted 30 September 2016: Final revision received 27 March 2017: Accepted 21 April 2017: First published online 20 June 2017

\begin{abstract}
Objective: To characterise German vitamin and mineral supplement users differentiated by their motives for supplement use.

Design: Data were obtained from the German National Nutrition Monitoring (2010/11) via two $24 \mathrm{~h}$ dietary recalls and a telephone interview. Motive-based subgroups of supplement users were identified by factor and cluster analysis. Sociodemographic, lifestyle, health and dietary characteristics and supplement use were examined. Differences were analysed using $\chi^{2}$ tests, logistic and linear regression models.

Setting: Germany, nationwide.

Subjects: Individuals ( $n$ 1589) aged $18-80$ years.

Results: Three motive-based subgroups were identified: a 'Prevention' subgroup ( $n$ 324), characterised by the motive to prevent nutrient deficiencies; a 'Prevention and additional benefits' subgroup ( $n$ 166), characterised by motives to prevent health problems and improve well-being and performance; and a 'Treatment' subgroup ( $n$ 136), characterised by motives to treat nutrient deficiencies or diseases. Members of the two prevention subgroups had a higher Healthy Eating Index score and tended to be more physically active than non-users. Those in the 'Prevention and additional benefits' subgroup supplemented with a greater number of micronutrients. Members of the 'Treatment' subgroup tended to be older and have a lower self-reported health status than non-users, and supplemented with a smaller number of micronutrients.

Conclusions: The majority of supplement users take supplements for preventive purposes and they are more health conscious than non-users of supplements due to their concerns about developing health problems. Those supplementing for treatment purposes may have underlying health indications and may be more likely to benefit from supplementation than those supplementing for preventive purposes.
\end{abstract}

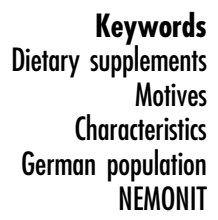

According to the results of the German National Nutrition Survey II (NVS II), which was conducted between 2005 and 2007, one-quarter of the German population regularly used vitamin and mineral supplements ${ }^{(1)}$. In 2011, more than 250 million Euros were spent on vitamin and mineral supplements in Germany ${ }^{(2)}$. The uncontrolled use of supplements in the general population may represent a health risk as there is increasing evidence that high intakes of some dietary supplements, such as vitamin $\mathrm{E}$ or vitamin A, may be more harmful than beneficial $^{(3-5)}$.

One common finding among studies on supplement use in Europe is that the major motives for supplement use are related to health ${ }^{(6-10)}$. Furthermore, it has been reported that supplement use is more frequent in women than in $\operatorname{men}^{(1,11,12)}$, in older people than in younger people ${ }^{(1,12)}$ and in people with higher levels of education compared with those with lower levels of education ${ }^{(13,14)}$. Supplement users tend to be more physically active ${ }^{(15,16)}$, less likely to smoke ${ }^{(7,15)}$, have a lower BMI ${ }^{(11,14)}$ and to make a healthier food choice ${ }^{(1,17,18)}$ than non-users.

However, little attention has been given to heterogeneity among supplement users. The majority of studies that examine the characteristics of supplement users simply compare users of dietary supplements with non-users. Recent investigations have shown that this dichotomous approach is likely to mask differences in sociodemographic, lifestyle, health and dietary characteristics among users of different types of dietary supplements ${ }^{(13,19)}$. The findings 
from these studies indicate that there is a need for more research on the similarities and differences among subgroups of supplement users. As motivation is a key factor that influences individual consumption behaviour ${ }^{(20)}$, examining individuals' motives for taking supplements is an important way of differentiating between subgroups of supplement users. Overall, it is of great interest to explore the heterogeneity among supplement users based on their motives for taking supplements.

Therefore, our study aimed to examine the motives for the use of vitamin and mineral supplements and to identify subgroups with similar motives among adult users of supplements in Germany. The study further aimed to investigate the sociodemographic, lifestyle, health and dietary characteristics of supplement users and the patterns of supplement use (frequency of use, types of supplements used, number of supplemented vitamins and minerals) among the overall group of supplement users as well as within the motive-based subgroups. The data for these analyses were obtained from the German National Nutrition Monitoring (NEMONIT).

\section{Methods}

\section{Study design and participants}

NEMONIT was a longitudinal survey that was carried out from 2008 to 2015, a detailed description of which has been published previously ${ }^{(21)}$. NEMONIT involved a sample of about 2000 participants aged 18-80 years who were recruited from NVS II, a study on the food consumption and nutrient intake of a representative sample of 14- to 80-yearold men and women in Germany ${ }^{(22)}$. The aim of NEMONIT was to monitor the food consumption of the adult population in Germany. Hence, food consumption, supplement use, and sociodemographic, lifestyle and health characteristics were assessed annually by two $24 \mathrm{~h}$ recall telephone interviews and an additional computer-assisted telephone interview. In 2010/11, additional information on supplement use regarding the frequency of supplement use and motives for taking supplements was collected.

All data used in the present study were derived from the NEMONIT assessments in 2010/11, in which 1623 participants completed two $24 \mathrm{~h}$ dietary recall interviews. Due to contradictory information on supplement use, thirty-four individuals were excluded. These participants reported vitamin and mineral supplement use in the $24 \mathrm{~h}$ recall interviews, but they denied supplement use in the previous 12 months when they were asked in the computer-assisted telephone interview. Thus, the total sample consisted of 1589 participants aged 18-80 years.

The survey was approved by the German Federal Data Protection Office. Respondents were informed in detail about the study objectives, interview procedures and the handling of data records and analyses under pseudonymous conditions. Participation was on a voluntary basis and could be withdrawn at any time. Participants provided informed written consent.

\section{Assessment of food consumption and supplement use}

Food consumption and supplement use were assessed via $24 \mathrm{~h}$ dietary recalls on two non-consecutive days. The dietary assessment programme EPIC-SOFT ${ }^{(23,24)}$ (which was renamed GloboDiet in 2014) was used during the interviews. With regard to supplements, the participants reported the product name, the pharmaceutical form and the dosage. Information on the nutrient content of the reported supplements was obtained from an internal supplement database. This database (which was updated for 2011) contained the product information for each supplement, such as product names and nutrient contents obtained from the packaging, the Internet or the manufacturer's reply to a written request.

In the present study, the term 'supplement' refers to supplements and drugs that predominantly contain vitamins and minerals. Several reported products that lack significant amounts of micronutrients were excluded from the analysis, such as prebiotics, probiotics, herbal products and homeopathic products. According to each supplement's product name and main micronutrient, the supplements were assigned to thirteen groups, e.g. to the 'magnesium' group if magnesium was the primary component, to the 'magnesium and calcium' group if both minerals where primary components (with no clear predominance) or to the 'multivitamin-mineral' group if the product contained a wide range of vitamins and at least one mineral. The number of vitamins and minerals supplemented by each individual was calculated using the information on the micronutrient composition of the supplements from the supplement database.

The quality of each participant's diet was measured using the Healthy Eating Index-NVS II (HEI-NVS II) ${ }^{(25)}$, which was adapted for use with $24 \mathrm{~h}$ dietary recalls. The index comprises ten components related to various food groups and macronutrients: (i) fruit/fruit products; (ii) vegetables; (iii) bread/cereals/potatoes; (iv) milk/cheese/other dairy products; (v) fish/seafood; (vi) meat/sausages; (vii) eggs; (viii) non-alcoholic beverages; (ix) alcohol; and (x) fat. The amounts of each component consumed were compared with the dietary recommendations of the German Nutrition Society ${ }^{(26,27)}$. Each of the components was given a maximum score of 10 points, except for fruit/fruit products and vegetables, which were each given a maximum score of 15 points. Higher scores indicate a closer accordance with the recommended nutrition amounts or ranges. Total HEI-NVS II scores were calculated by summing the scores of each of the ten components. The maximum score is 110 points, which indicates that the individual's diet follows the recommendations precisely (for more information see Gose et $\left.a l^{(21)}\right)$. Each participant's energy and nutrient intake from foods was calculated based on the German Nutrient Database (BLS) $3.02^{(28)}$. 


\section{Frequency and motives of supplement use}

The participants took part in a computer-assisted telephone interview during which they were asked whether they had used any vitamin and/or mineral supplements in the previous 12 months. Those who had used supplements were asked about their frequency of use (there were four potential responses ranging from 'daily' to 'one or more times per year'). Data on the participants' motives for taking supplements were collected by asking the participants to select from a list of ten possible motives. Participants were allowed to select multiple options and to provide additional motives.

\section{Sociodemographic, lifestyle and bealth characteristics}

Sociodemographic data (such as data on sex, age, school education and number of people living in the individual's household) were also collected during the computerassisted telephone interview. In addition, participants were asked about their smoking status and whether they had a special diet (such as a vegetarian diet). BMI was calculated using self-reported height and weight and the participants were asked about the number of hours they spent on sports activities per week. They were also asked to assess their own health status (there were four potential responses ranging from 'very good' to 'poor').

\section{Statistical analysis}

Descriptive statistics were calculated as percentages for the categorical variables and as means (with standard deviations) for the continuous variables. The differences in the prevalence rates between groups were assessed using Pearson's $\chi^{2}$ analyses and the differences in the means of the continuous variables were assessed using one-way ANOVA.

To identify motive-based subgroups of supplement users, both a factor analysis and a cluster analysis were used. First, a principal component factor analysis with varimax rotation was carried out to reduce the large number of inter-correlated motives to a small number of independent factors. These underlying factors represented the motives that were highly correlated and frequently reported in combination. The analysis was based on a tetrachoric correlation matrix, which is an appropriate method for use with dichotomous data ${ }^{(29)}$. For each supplement user, factor scores were calculated using a least-squares regression approach ${ }^{(30)}$. Second, to generate subgroups of supplement users with homogeneous motives, a cluster analysis was carried out using the squared Euclidean distance as the distance measure. The standardised factor scores ( $Z$-scores) obtained from factor analysis were used as entities in the cluster analysis. The optimal number of clusters was evaluated using a dendrogram and the pseudo- $F$ statistic of Ward's hierarchical $\operatorname{method}^{(31,32)}$. Cluster allocation was carried out using a non-hierarchical $k$-means method with the initial centroids obtained from Ward's method ${ }^{(33)}$.

Multivariate logistic regression analyses were conducted to assess the independent association of each sociodemographic, lifestyle and health characteristic (independent variables) with supplement use (dependent variable) for the overall group of supplement users as well as for each motive-based subgroup. Multivariate general linear models with the total HEI-NVS II score or dietary energy or nutrient intake as dependent variables and group membership as independent variable were used to compare the dietary characteristics between groups of supplements users and non-users, adjusted for potential confounders.

The analyses were carried out using the statistical software package IBM SPSS Statistics for Windows version 20.0 except for the tetrachoric correlation matrix analysis, which was carried out using SAS version 9.3. Statistical significance (based on two-tailed significant tests) was defined as a $P$ value of less than $0 \cdot 05$.

\section{Results}

Of the 1589 participants, 58.0\% were female. The mean age of the study population was $54 \cdot 1$ (SD 15.1) years and the mean BMI was 25.7 (sD 4.5 ) $\mathrm{kg} / \mathrm{m}^{2}$. Forty per cent were identified as supplement users, having taken vitamin and/or mineral supplements at least once during the previous 12 months. Supplement use was more common in women $(44.7 \%)$ than in men $(34.0 \%)$. A further description of the study sample is presented in Table 1.

The most frequently reported motive for supplement use was 'prevention of nutrient deficiencies', which was reported by more than $60 \%$ of the supplement users (Table 2). The motives 'disease prevention' and 'achievement or improvement of general well-being' were each reported by a third of the sample. Women reported the motives of 'disease prevention' and 'good appearance' more often than men. Sixty per cent of the supplement users selected more than one motive for taking supplements.

For the identification of motive-based subgroups of supplement users, a two-step approach was used. At first, to explore which motives were reported in combination, a principal component factor analysis was carried out. Two distinct factors were identified, which explained $57.9 \%$ of the total variance (see online supplementary material, Supplemental Table 1). As indicated by strong positive factor loadings, factor 1 represented the combination of the motives 'enhancement of physical or mental performance', 'achievement or improvement of general well-being', 'disease prevention' and 'compensation for inadequate dietary intake'. Respectively, factor 2 represented the combination of the motives 'support of disease treatment' and 'treatment of nutrient deficiencies'. In addition, 'prevention of nutrient deficiencies' had a strong negative factor loading on factor 2 , which means that this 
Table 1 Characteristics of the study sample of the German National Nutrition Monitoring (NEMONIT), survey year 2010/11

\begin{tabular}{|c|c|c|c|}
\hline Characteristic & Total & Male & Female \\
\hline Age group (\%) & n 1589 & $n 668$ & $n 921$ \\
\hline $18-34$ years & $12 \cdot 1$ & $12 \cdot 3$ & 11.9 \\
\hline $35-50$ years & 28.5 & $25 \cdot 1$ & $30 \cdot 9$ \\
\hline $51-64$ years & 31.5 & 31.3 & 31.6 \\
\hline $65-80$ years & 27.9 & 31.3 & $25 \cdot 5$ \\
\hline School education (\%) & $n 1589$ & $n 668$ & $n 921$ \\
\hline$\leq 9$ years & $26 \cdot 9$ & 26.5 & $27 \cdot 1$ \\
\hline 10 years & 32.6 & $27 \cdot 2$ & 36.5 \\
\hline $12 / 13$ years & 40.5 & $46 \cdot \overline{3}$ & $36 \cdot 4$ \\
\hline \multirow{3}{*}{$\begin{array}{l}\text { Number of people living in } \\
\text { household (\%) } \\
1 \\
2\end{array}$} & $n 1587$ & $n 667$ & $n 920$ \\
\hline & 14.6 & 13.0 & $15 \cdot 7$ \\
\hline & 47.5 & $46 \cdot 9$ & 47.9 \\
\hline$\geq 3$ & 37.9 & $40 \cdot 0$ & $36 \cdot 4$ \\
\hline BMI $\left(\mathrm{kg} / \mathrm{m}^{2}\right)$ & $n 1587$ & $n 666$ & $n 921$ \\
\hline Mean & $25 \cdot 7$ & $26 \cdot 7$ & $25 \cdot 1$ \\
\hline SD & 4.5 & 3.8 & 4.8 \\
\hline Sports activities (h/week) & $n 1557$ & $n 657$ & $n 900$ \\
\hline Mean & 3.7 & 4.4 & $3 \cdot 2$ \\
\hline SD & $5 \cdot 1$ & $6 \cdot 0$ & $4 \cdot 2$ \\
\hline \multirow[t]{2}{*}{ Regular smoking (\%) } & $n 1589$ & $n 668$ & $n 921$ \\
\hline & 11.6 & 11.7 & 11.6 \\
\hline \multirow[t]{2}{*}{ Special diet (\%) } & $n 1589$ & $n 668$ & n 921 \\
\hline & 3.0 & $1 \cdot 8$ & 3.8 \\
\hline Self-reported health status (\%) & $n 1587$ & $n 667$ & $n 920$ \\
\hline Poor & $2 \cdot 5$ & $2 \cdot 1$ & $2 \cdot 7$ \\
\hline Moderate & $15 \cdot 8$ & $15 \cdot 6$ & $16 \cdot 0$ \\
\hline Good & $60 \cdot 6$ & 63.4 & 58.5 \\
\hline Very good & $21 \cdot 2$ & $18 \cdot 9$ & $22 \cdot 8$ \\
\hline HEI-NVS II score & $n 1589$ & $n 668$ & $n 921$ \\
\hline Mean & 68.5 & $66 \cdot 6$ & 69.9 \\
\hline SD & $10 \cdot 3$ & $10 \cdot 7$ & $9 \cdot 8$ \\
\hline Vitamin and/or mineral & $n 1589$ & $n 668$ & $n 921$ \\
\hline $\begin{array}{l}\text { supplement use in the } \\
\text { past } 12 \text { months }(\%)\end{array}$ & $40 \cdot 2$ & $34 \cdot 0$ & $44 \cdot 7$ \\
\hline
\end{tabular}

HEI-NVS II, Healthy Eating Index of the German National Nutrition Survey II.

Table 2 Motives for supplement use among supplement users; the German National Nutrition Monitoring (NEMONIT), survey year 2010/11

\begin{tabular}{|c|c|c|c|c|}
\hline & $\begin{array}{l}\text { Total } \\
(n \text { 639) }\end{array}$ & $\begin{array}{l}\text { Male } \\
(n \text { 227) }\end{array}$ & $\begin{array}{l}\text { Female } \\
(n \text { 412) }\end{array}$ & \\
\hline Motive & $\%$ & $\%$ & $\%$ & $P\left(x^{2}\right) \dagger$ \\
\hline $\begin{array}{l}\text { Prevention of nutrient } \\
\text { deficiencies (or covering } \\
\text { increased nutrient requirements) }\end{array}$ & $62 \cdot 4$ & 63.4 & 61.9 & 0.700 \\
\hline Disease prevention & 34.9 & 29.5 & 37.9 & 0.034 \\
\hline $\begin{array}{l}\text { Achievement or improvement } \\
\text { of general well-being }\end{array}$ & 34.7 & $32 \cdot 2$ & $36 \cdot 2$ & 0.309 \\
\hline $\begin{array}{l}\text { Treatment of nutrient } \\
\text { deficiencies }\end{array}$ & 28.6 & $25 \cdot 6$ & $30 \cdot 3$ & 0.200 \\
\hline $\begin{array}{l}\text { Enhancement of physical } \\
\text { or mental performance }\end{array}$ & $27 \cdot 7$ & $27 \cdot 8$ & $27 \cdot 7$ & 0.982 \\
\hline Support of disease treatment & 26. & $25 \cdot 6$ & 26 & 0.803 \\
\hline $\begin{array}{l}\text { Compensation for inadequate } \\
\text { dietary intake }\end{array}$ & $26 \cdot 0$ & $22 \cdot 0$ & $28 \cdot 2$ & 0.091 \\
\hline $\begin{array}{l}\text { Good appearance } \\
\text { Prevention of allergies }\end{array}$ & $\begin{array}{l}8.3 \\
5 \cdot 6\end{array}$ & $\begin{array}{l}3 \cdot 1 \\
3.5\end{array}$ & $\begin{array}{r}11 \cdot 2 \\
6 \cdot 8\end{array}$ & $\begin{array}{r}<0.001 \\
0.086\end{array}$ \\
\hline Support of skin tanning & 0.5 & 0.0 & 0.7 & 0.198 \\
\hline
\end{tabular}

$\dagger P$ values from Pearson's $X^{2}$ analyses of the differences between male and female supplement users.

motive was extremely rarely reported in combination with the two motives associated with treatment.

Based on the standardised factor scores from the factor analysis, in the second step a cluster analysis was used to classify the supplement users into subgroups. The optimal number of clusters was determined using Ward's hierarchical approach, which indicated that a three-cluster solution was the best fit for the data. Therefore, three subgroups of supplement users were generated using a $k$-means analysis (see online supplementary material, Supplemental Table 2). Cluster 1, which contained 324 $(51 \cdot 8 \%)$ of the participants, was the largest subgroup. Clusters 2 and 3 had 166 (26.5\%) and 134 (21.7\%) participants, respectively. The clusters were labelled according to the principal motives of the cluster members. Cluster 1 was labelled 'Prevention', as the motive 'prevention of nutrient deficiencies' was reported by more than three-quarters of the cluster members. The other nine motives were each reported by less than a quarter of the cluster members (Table 3). Cluster 2 was labelled 'Prevention and additional benefits', as two preventive motives ('prevention of nutrient deficiencies' and 'disease prevention') and three motives concerning additional benefits ('achievement or improvement of general wellbeing', 'enhancement of physical or mental performance' and 'compensation for inadequate dietary intake') were each reported by more than half of the members. Cluster 3 was labelled 'Treatment', as 'treatment of nutrient deficiencies' and 'support of disease treatment' were each reported by about two-thirds of the cluster members, while the other eight motives were each reported by less than a quarter of the members. Many of the respondents in the 'Prevention' and 'Treatment' subgroups ( 58.0 and $47.8 \%$, respectively) reported only one motive for taking supplements. However, in the 'Prevention and additional benefits' subgroup, none of the respondents stated only one motive and $60 \cdot 2 \%$ reported five or more motives.

The sociodemographic, lifestyle and health characteristics of the groups of supplement users in comparison to non-users are described in Table 4. Supplement users were more likely to be women, older, spend more time on sports activities and to have a special diet like a vegetarian diet. Comparisons of the motive-based subgroups of supplement users and non-users showed that those who had a special diet were up to three times more likely to be in the 'Prevention' or 'Prevention and additional benefits' subgroup than the non-users group, while there was no difference between those in the 'Treatment' subgroup and non-users. Participants in the 'Prevention and additional benefits' subgroup also tended to spend more time on sports activities than non-users. In addition, in the 'Prevention' subgroup, a tendency to spend a larger amount of time on sports activities than that spent by non-users was observed $(P=0 \cdot 07)$. Furthermore, only the participants in the 'Treatment' subgroup were more likely to be older and to report a poor health status than non-users. Independent of the motive-based subgroups, women were more likely to be supplement users than non-users, whereas school education, the number of people living in the participant's 
Table 3 Motives for supplement use among motive-based clusters of supplement users; the German National Nutrition Monitoring (NEMONIT), survey year 2010/11

\begin{tabular}{|c|c|c|c|c|}
\hline & $\begin{array}{l}\text { Cluster 1 } \\
\text { 'Prevention' } \\
(n \text { 324) } \\
\end{array}$ & $\begin{array}{c}\text { Cluster } 2 \\
\text { 'Prevention and additional } \\
\text { benefits' } \\
(n 166) \\
\end{array}$ & $\begin{array}{c}\text { Cluster } 3 \\
\text { 'Treatment' } \\
(n 136) \\
\end{array}$ & \\
\hline Motive & $\%$ & $\%$ & $\%$ & $P\left(x^{2}\right) \dagger$ \\
\hline Prevention of nutrient deficiencies & $75 \cdot 9$ & $82 \cdot 5$ & $11 \cdot 8$ & $<0.001$ \\
\hline Disease prevention & $21 \cdot 0$ & $74 \cdot 7$ & $22 \cdot 8$ & $<0.001$ \\
\hline $\begin{array}{l}\text { Achievement or improvement of general } \\
\text { well-being }\end{array}$ & $15 \cdot 1$ & $85 \cdot 5$ & $22 \cdot 8$ & $<0.001$ \\
\hline Treatment of nutrient deficiencies & $12 \cdot 0$ & 31.3 & $67 \cdot 6$ & $<0.001$ \\
\hline $\begin{array}{l}\text { Enhancement of physical or mental } \\
\text { performance }\end{array}$ & $7 \cdot 4$ & $83 \cdot 7$ & $10 \cdot 3$ & $<0.001$ \\
\hline Support of disease treatment & $4 \cdot 3$ & $42 \cdot 8$ & $60 \cdot 3$ & $<0.001$ \\
\hline $\begin{array}{l}\text { Compensation for inadequate dietary } \\
\text { intake }\end{array}$ & $20 \cdot 1$ & $56 \cdot 0$ & $5 \cdot 9$ & $<0.001$ \\
\hline Good appearance & $2 \cdot 8$ & $24 \cdot 1$ & $2 \cdot 2$ & $<0.001$ \\
\hline Prevention of allergies & $3 \cdot 1$ & $12 \cdot 0$ & 1.5 & $<0.001$ \\
\hline Support of skin tanning & 0.3 & $1 \cdot 2$ & 0.0 & 0.261 \\
\hline
\end{tabular}

Prevalence rates above $50.0 \%$ are indicated in bold font.

$\dagger P$ values from Pearson's $x^{2}$ analyses of the differences between the three clusters.

Table 4 Sociodemographic, lifestyle and health characteristics of groups of supplement users compared with non-users (= base outcome), depicted as OR from logistic regression models; the German National Nutrition Monitoring (NEMONIT), survey year 2010/11†,‡

\begin{tabular}{|c|c|c|c|c|c|c|c|c|}
\hline \multirow[b]{3}{*}{ Characteristic } & \multirow{2}{*}{\multicolumn{2}{|c|}{$\begin{array}{l}\text { Overall group of } \\
\text { supplement users } \\
(n 606)\end{array}$}} & \multicolumn{6}{|c|}{ Motive-based cluster of supplement users } \\
\hline & & & \multicolumn{2}{|c|}{$\begin{array}{l}\text { 'Prevention' subgroup } \\
\text { (n 314) }\end{array}$} & \multicolumn{2}{|c|}{$\begin{array}{c}\text { 'Prevention and } \\
\text { additional benefits' } \\
\text { subgroup } \\
(n 160)\end{array}$} & \multicolumn{2}{|c|}{$\begin{array}{c}\text { 'Treatment' subgroup } \\
\text { ( } n \text { 132) }\end{array}$} \\
\hline & $\begin{array}{l}\text { Adjusted } \\
\text { OR }\end{array}$ & $95 \% \mathrm{Cl}$ & $\begin{array}{l}\text { Adjusted } \\
\text { OR }\end{array}$ & $95 \% \mathrm{Cl}$ & $\begin{array}{l}\text { Adjusted } \\
\text { OR }\end{array}$ & $95 \% \mathrm{Cl}$ & $\begin{array}{l}\text { Adjusted } \\
\text { OR }\end{array}$ & $95 \% \mathrm{Cl}$ \\
\hline Female (\%) & $1.66^{\star \star \star}$ & $1.33,2.08$ & $1.44^{\star *}$ & $1 \cdot 10,1.90$ & $1 \cdot 80^{\star *}$ & $1 \cdot 24,2 \cdot 60$ & $2 \cdot 21^{\star \star \star}$ & $1.46,3.36$ \\
\hline Age (years) & $1.01^{\star *}$ & $1.00,1.02$ & 1.01 & $1.00,1.02$ & 1.00 & $1.00,1.02$ & $1.04^{\star * *}$ & $1.02,1.05$ \\
\hline \multicolumn{9}{|l|}{ School education (\%) } \\
\hline$\leq 9$ years & 1.01 & $0.76,1.34$ & 0.95 & $0.67,1.35$ & $1 \cdot 18$ & $0.75,1.86$ & 0.97 & $0.59,1.59$ \\
\hline 10 years & \multirow{2}{*}{\multicolumn{2}{|c|}{$\begin{array}{l}1.05 \text { Ref. } \\
\quad 0.81,1.35\end{array}$}} & \multirow{2}{*}{\multicolumn{2}{|c|}{1.05 Ref. }} & \multirow{2}{*}{\multicolumn{2}{|c|}{ Ref. }} & 1.04 & $0.65,1.64$ \\
\hline $12 / 13$ years & & & & & & & \multicolumn{2}{|c|}{ Ref. } \\
\hline $\begin{array}{l}\text { Number of people living in } \\
\text { household }\end{array}$ & 0.96 & $0.87,1.06$ & 0.92 & $0.81,1.04$ & 0.97 & $0.83,1.14$ & $1 \cdot 10$ & $0.91,1.34$ \\
\hline BMl $\left(\mathrm{kg} / \mathrm{m}^{2}\right)$ & 0.99 & $0.97,1.02$ & 1.00 & $0.97,1.03$ & 0.99 & $0.95,1.03$ & 0.98 & $0.94,1.02$ \\
\hline Sports activities (h/week) & $1.02^{*}$ & $1.00,1.05$ & 1.02 & $1.00,1.05$ & $1.04^{*}$ & $1.01,1.07$ & 0.99 & $0.95,1.04$ \\
\hline Regular smoking (\%) & 0.78 & $0.56,1.10$ & 0.70 & $0.45,1.09$ & 1.03 & $0.62,1.72$ & 0.70 & $0.36,1.36$ \\
\hline Special diet (\%) & $2 \cdot 32^{\star *}$ & $1 \cdot 24,4.34$ & $3.01^{* *}$ & $1.51,6.01$ & $2 \cdot 48^{\star}$ & $1.04,5.91$ & 0.41 & $0.05,3.19$ \\
\hline \multicolumn{9}{|c|}{ Self-reported health status (\%) } \\
\hline Poor & 1.81 & $0.89,3.67$ & 0.73 & $0.26,2 \cdot 10$ & 2.52 & $0.89,7.13$ & $5 \cdot 60^{\star \star}$ & $1.98,15 \cdot 86$ \\
\hline Moderate & 1.16 & $0.81,1.67$ & 0.64 & $0.40,1.04$ & 1.74 & $0.98,3.07$ & $2 \cdot 61^{\text {** }}$ & $1.30,5.27$ \\
\hline Good & 1.23 & $0.94,1.62$ & 1.06 & $0.77,1.46$ & 1.27 & $0.81,1.99$ & $2 \cdot 04^{*}$ & $1 \cdot 12,3.73$ \\
\hline Very good & \multicolumn{2}{|c|}{ Ref. } & \multicolumn{2}{|c|}{ Ref. } & \multicolumn{2}{|c|}{ Ref. } & \multicolumn{2}{|c|}{ Ref. } \\
\hline
\end{tabular}

Ref., reference category.

${ }^{\star} P<0.05,{ }^{\star *} P<0.01,{ }^{\star \star *} P<0.001$.

†OR were estimated for the total group of supplement users using a binominal logistic regression model and for the clusters using a multinomial logistic regression model. All variables presented in the table were mutually adjusted for. The non-users of supplements ( $n$ 932) were used as base outcome in the regression models.

‡Participants with missing values for any of the independent variables were excluded from the models $(n 38)$.

household, regular smoking and BMI were not associated with supplement use.

Supplement users tended to have a higher total HEINVS II score (Table 5). The $\beta$ coefficient of 1.77 indicates that the HEI-NVS II score was 1.77 higher in supplement users compared with non-users. Examining the nutrient intake from food alone without considering the contribution from supplements, the intake of dietary fibre, vitamin $\mathrm{E}$, folate, vitamin $\mathrm{B}_{12}, \mathrm{Mg}$ and $\mathrm{Fe}$ was significantly higher in supplement users than in non-users. Similar findings were observed for the two prevention subgroups in comparison to non-users. The higher total HEI-NVS II scores were 
Table 5 Total HEI-NVS II score and energy and nutrient intake from food in supplement users compared with non-users (= reference group), depicted as $\beta$ coefficients from general linear models conducted separately for total HEI-NVS II score and each dietary intake variable; the German National Nutrition Monitoring (NEMONIT), survey year 2010/11†,‡

\begin{tabular}{|c|c|c|c|c|c|c|c|c|}
\hline \multirow[b]{3}{*}{ Dietary variable } & \multirow{2}{*}{\multicolumn{2}{|c|}{$\begin{array}{l}\text { Overall group of } \\
\text { supplement users } \\
(n 606)\end{array}$}} & \multicolumn{6}{|c|}{ Motive-based cluster of supplement users } \\
\hline & & & \multicolumn{2}{|c|}{$\begin{array}{l}\text { ‘Prevention' subgroup } \\
\text { ( } n \text { 314) }\end{array}$} & \multicolumn{2}{|c|}{$\begin{array}{l}\text { 'Prevention and additional } \\
\text { benefits' subgroup } \\
(n 160)\end{array}$} & \multicolumn{2}{|c|}{$\begin{array}{l}\text { 'Treatment' subgroup } \\
\text { ( } n \text { 132) }\end{array}$} \\
\hline & $\begin{array}{c}\text { Adjusted } \\
\beta\end{array}$ & $95 \% \mathrm{Cl}$ & $\begin{array}{c}\text { Adjusted } \\
\beta\end{array}$ & $95 \% \mathrm{Cl}$ & $\begin{array}{c}\text { Adjusted } \\
\beta\end{array}$ & $95 \% \mathrm{Cl}$ & $\begin{array}{c}\text { Adjusted } \\
\beta\end{array}$ & $95 \% \mathrm{Cl}$ \\
\hline $\begin{array}{l}\text { Total HEI-NVS II } \\
\text { score }\end{array}$ & $1 \cdot 77^{\star \star}$ & $0 \cdot 74,2 \cdot 81$ & $1.83^{\star \star}$ & $0.54,3.12$ & $1 \cdot 87^{*}$ & $0.19,3.56$ & 1.50 & $-0.35,3.35$ \\
\hline Energy (kJ/d) & $188 \cdot 20$ & $-73.95,450 \cdot 34$ & 113.53 & $-211.96,439.02$ & 111.38 & $-315 \cdot 38,538 \cdot 14$ & $469 \cdot 95^{\star}$ & $1.56,938.33$ \\
\hline Protein $(E \% / d)$ & 0.13 & $-0.23,0.48$ & 0.32 & $-0.12,0.76$ & -0.06 & $-0.63,0.52$ & -0.13 & $-0.76,0.50$ \\
\hline Fat $(E \% / d)$ & -0.40 & $-1.14,0.35$ & -0.76 & $-1.69,0.16$ & 0.17 & $-1.04,1.38$ & -0.20 & $-1.53,1.13$ \\
\hline Carbohydrate $(E \% / d)$ & 0.53 & $-0.33,1.38$ & 0.80 & $-0.27,1.86$ & $0 \cdot 10$ & $-1.30,1.49$ & 0.39 & $-1 \cdot 14,1.92$ \\
\hline Alcohol $(E \% / d)$ & -0.26 & $-0.79,0.27$ & -0.36 & $-1.02,0.30$ & -0.22 & $-1.08,0.65$ & -0.05 & $-1.00,0.89$ \\
\hline Fibre $(g / d)$ & $1.43^{\star \star}$ & $0.58,2.23$ & $1 \cdot 85^{\star \star}$ & $0.80,2.90$ & 0.94 & $-0.44,2 \cdot 32$ & 0.99 & $-0.53,2.50$ \\
\hline Vitamin A (RE; mg/d) & 0.09 & $-0.16,0.34$ & $-0 \cdot 10$ & $-0.41,0.21$ & $0.50^{*}$ & $0.10,0.91$ & 0.05 & $-0.39,0.49$ \\
\hline Vitamin D ( $\mu \mathrm{g} / \mathrm{d})$ & 0.43 & $-0.02,0.88$ & 0.51 & $-0.05,1.07$ & 0.43 & $-0.31,1 \cdot 16$ & 0.23 & $-0.57,1.04$ \\
\hline Vitamin E (TE; mg/d) & $0 \cdot 90^{\star *}$ & $0.30,1.50$ & $0.89^{*}$ & $0.14,1.63$ & 0.87 & $-0.11,1.85$ & 0.95 & $-0.12,2.03$ \\
\hline Vitamin $C(\mathrm{mg} / \mathrm{d})$ & $6 \cdot 40$ & $-0.77,13.57$ & 6.02 & $-2 \cdot 88,14.93$ & 6.85 & $-4.83,18.53$ & $6 \cdot 77$ & $-6.05,19.58$ \\
\hline Thiamin (mg/d) & 0.03 & $-0.04,0.09$ & 0.04 & $-0.04,0.12$ & -0.01 & $-0.12,0.09$ & 0.04 & $-0.07,0.15$ \\
\hline Riboflavin (mg/d) & 0.04 & $-0.02,0.10$ & 0.04 & $-0.03,0.12$ & 0.01 & $-0.09,0.11$ & 0.08 & $-0.03,0.19$ \\
\hline Niacin (NE; mg/d) & 0.38 & $-0.77,1.53$ & 0.57 & $-0.86,1.99$ & -0.35 & $-2 \cdot 22,1.51$ & 0.83 & $-1.21,2.88$ \\
\hline Vitamin $B_{6}(\mathrm{mg} / \mathrm{d})$ & 0.05 & $-0.02,0.12$ & 0.08 & $-0.01,0.16$ & -0.01 & $-0.12,0.10$ & 0.08 & $-0.05,0.20$ \\
\hline Folate (FE; $\mu \mathrm{g} / \mathrm{d})$ & $14 \cdot 24^{\star \star}$ & $4.55,23.94$ & $14.96^{\star}$ & $2 \cdot 92,27 \cdot 00$ & $12 \cdot 22$ & $-3.57,28.01$ & 14.99 & $-2 \cdot 34,32 \cdot 32$ \\
\hline Vitamin $B_{12}(\mu \mathrm{g} / \mathrm{d})$ & $0.52^{*}$ & $0.05,0.99$ & 0.07 & $-0.52,0.65$ & $1.34^{\star \star}$ & $0.58,2 \cdot 11$ & 0.63 & $-0.22,1.47$ \\
\hline $\mathrm{Ca}(\mathrm{mg} / \mathrm{d})$ & $31 \cdot 14$ & $-3 \cdot 46,65 \cdot 73$ & $37 \cdot 17$ & $-5 \cdot 79,80 \cdot 12$ & 0.54 & $-55 \cdot 78,56 \cdot 86$ & 54.53 & $-7 \cdot 29,116 \cdot 34$ \\
\hline $\mathrm{Mg}(\mathrm{mg} / \mathrm{d})$ & $14 \cdot 82^{\star *}$ & $4.44,25 \cdot 20$ & $18 \cdot 85^{\star \star}$ & $5 \cdot 96,31.75$ & 8.62 & $-8.28,25.53$ & 12.57 & $-5.99,31.13$ \\
\hline $\mathrm{Fe}(\mathrm{mg} / \mathrm{d})$ & $0.54^{\star}$ & $0.11,0.98$ & $0.54^{\star}$ & $0.00,1.08$ & 0.67 & $-0.04,1.37$ & 0.40 & $-0.37,1.18$ \\
\hline lodine $(\mu \mathrm{g} / \mathrm{d})$ & -0.59 & $-6 \cdot 53,5.35$ & $-2 \cdot 30$ & $-9.68,5.07$ & -0.95 & $-10 \cdot 62,8 \cdot 72$ & $4 \cdot 10$ & $-6 \cdot 52,14.71$ \\
\hline $\mathrm{Zn}(\mathrm{mg} / \mathrm{d})$ & 0.36 & $-0.01,0.72$ & 0.37 & $-0.09,0.83$ & 0.15 & $-0.45,0.75$ & 0.58 & $-0.08,1.24$ \\
\hline
\end{tabular}

HEI-NVS II, Healthy Eating Index of the German National Nutrition Survey II; E\%, percentage of energy; RE, retinol equivalents; TE, tocopherol equivalents; $\mathrm{NE}$, niacin equivalents; $\mathrm{FE}$, folate equivalents.

${ }^{\star} P<0.05,{ }^{\star *} P<0.01$.

†General linear models were performed separately for the total HEI-NVS II score and each dietary intake variable as dependent variables, adjusted for sex, age (years), time spent on sports activities (h/week) and self-reported health status (very good, good, moderate and poor), and with non-users of supplements ( $n$ 932) as reference group. A positive coefficient value of 1.43 for fibre intake, for example, indicates a $1.43 \mathrm{~g}$ higher daily intake of fibre in the group of supplement users compared with non-users.

$\ddagger$ Participants with missing values for any of the independent variables were excluded from the models $(n 38)$.

accompanied by a higher intake of dietary fibre, vitamin $\mathrm{E}$, folate, $\mathrm{Mg}$ and $\mathrm{Fe}$ in the 'Prevention' subgroup, and a higher dietary intake of vitamin $\mathrm{A}$ and vitamin $\mathrm{B}_{12}$ in the 'Prevention and additional benefits' subgroup. However, no differences were observed regarding the total HEI-NVS II score or micronutrient intake between the 'Treatment' subgroup and non-users, even though energy intake was higher in the 'Treatment' subgroup.

Regarding the frequency of supplement use, half of the supplement users reported taking supplements daily, while a tenth of the users reported taking supplements one or more times per year but less than monthly (Table 6). Comparisons of the frequency of use between each of the motive-based subgroups indicated no differences. With regard to the types of supplements used, overall, magnesium products were the most frequently used supplements, followed by multivitaminmineral products and calcium products. This was also true for the 'Prevention' and 'Prevention and additional benefits' subgroups. However, in the 'Treatment' subgroup, calcium products were used more often than multivitamin-mineral products. Furthermore, the use of vitamin B products was more pronounced in the 'Prevention' and 'Prevention and additional benefits' subgroups than in the 'Treatment' subgroup, and the use of multivitamin-mineral products and vitamin $\mathrm{C}$ and zinc products was particularly high in the 'Prevention and additional benefits' subgroup.

Regarding the number of supplemented vitamins and minerals, the majority of supplement users took up to four vitamins and minerals during the two $24 \mathrm{~h}$ dietary recall periods. However, nearly a quarter supplemented with ten or more micronutrients. Regarding the motive-based subgroups, supplementation with ten or more micronutrients was more pronounced in the 'Prevention and additional benefits' subgroup than in the other two subgroups, with almost one-third of those in the 'Prevention and additional benefits' subgroup. In contrast, in the 'Treatment' subgroup, three-quarters of users supplemented with up to four micronutrients and only $14 \cdot 1 \%$ supplemented with ten or more micronutrients. 
Table 6 Frequency and types of supplements used and number of supplemented vitamins and minerals in groups of supplement users; the German National Nutrition Monitoring (NEMONIT), survey year 2010/11

\begin{tabular}{|c|c|c|c|c|c|}
\hline & \multirow[b]{2}{*}{$\begin{array}{l}\text { Overall group of } \\
\text { supplement users }\end{array}$} & \multicolumn{3}{|c|}{ Motive-based cluster of supplement users } & \multirow[b]{3}{*}{$P\left(x^{2}\right) \dagger$} \\
\hline & & $\begin{array}{l}\text { 'Prevention' } \\
\text { subgroup }\end{array}$ & $\begin{array}{l}\text { 'Prevention and additional } \\
\text { benefits' subgroup }\end{array}$ & $\begin{array}{l}\text { 'Treatment' } \\
\text { subgroup }\end{array}$ & \\
\hline & $\%$ & $\%$ & $\%$ & $\%$ & \\
\hline Frequency of supplement useł & $n 624$ & $n 322$ & $n 166$ & $n 136$ & \\
\hline Daily & 51.3 & $52 \cdot 2$ & 48.2 & $52 \cdot 9$ & 0.642 \\
\hline $\begin{array}{l}\text { One or more times per week } \\
\text { (but less than daily) }\end{array}$ & $22 \cdot 1$ & $21 \cdot 7$ & $25 \cdot 9$ & $18 \cdot 4$ & 0.285 \\
\hline $\begin{array}{l}\text { One or more times per month } \\
\text { (but less than weekly) }\end{array}$ & $16 \cdot 0$ & $17 \cdot 1$ & $15 \cdot 1$ & $14 \cdot 7$ & 0.757 \\
\hline $\begin{array}{l}\text { One or more times per year } \\
\text { (but less than monthly) }\end{array}$ & $10 \cdot 7$ & $9 \cdot 0$ & $10 \cdot 8$ & $14 \cdot 0$ & 0.285 \\
\hline Type of supplement§ & n 404 & $n 210$ & n 109 & $n 85$ & \\
\hline Multivitamin & 8.4 & 8.6 & $7 \cdot 3$ & 9.4 & 0.869 \\
\hline Multivitamin-mineral & $15 \cdot 1$ & 13.8 & $22 \cdot 0$ & $9 \cdot 4$ & 0.039 \\
\hline Vitamin C & 7.2 & 6.2 & 9.2 & $7 \cdot 1$ & 0.618 \\
\hline Vitamin $\mathrm{C}$ and zinc & $5 . \overline{9}$ & $5 \cdot \overline{7}$ & $10 \cdot 1$ & 1.2 & 0.033 \\
\hline $\begin{array}{l}\text { B vitamins (single vitamin or } \\
\text { complex) }\end{array}$ & $10 \cdot 1$ & $12 \cdot 9$ & $11 \cdot 0$ & $2 \cdot 4$ & 0.024 \\
\hline Other single vitamin & 6.9 & $6 \cdot 2$ & $8 \cdot 3$ & $7 \cdot 1$ & 0.788 \\
\hline Magnesium & $46 \cdot 8$ & $48 \cdot 1$ & $45 \cdot 9$ & $44 \cdot 7$ & 0.848 \\
\hline Calcium & 14.6 & $13 \cdot 3$ & 17.4 & $14 \cdot 1$ & 0.611 \\
\hline Magnesium and calcium & $3 \cdot 7$ & 2.9 & 3.7 & 5.9 & 0.491 \\
\hline Calcium and vitamin D & $7 \cdot 4$ & 7.6 & $5 \cdot 5$ & 9.4 & 0.581 \\
\hline Iron & 4.0 & 3.3 & 5.5 & 3.5 & 0.624 \\
\hline Zinc & 3.5 & 2.9 & 3.7 & 4.7 & 0.727 \\
\hline Other single mineral & $6 \cdot 9$ & $9 \cdot 0$ & 4.6 & 4.7 & 0.219 \\
\hline $\begin{array}{l}\text { Number of supplemented } \\
\text { vitamins and/or minerals§ }\end{array}$ & n 404 & $n 210$ & $n 109$ & $n 85$ & \\
\hline $1-4$ & $64 \cdot 6$ & 63.8 & $57 \cdot 8$ & $75 \cdot 3$ & 0.039 \\
\hline $5-9$ & 12.6 & $13 \cdot 3$ & $12 \cdot 8$ & $10 \cdot 6$ & 0.811 \\
\hline$\geq 10$ & $22 \cdot 8$ & 22.9 & $29 \cdot 4$ & $14 \cdot 1$ & 0.043 \\
\hline
\end{tabular}

$\dagger P$ values from Pearson's $X^{2}$ analyses of the differences between the three clusters.

$\ddagger$ Assessed via a computer-assisted telephone interview.

$\S$ Assessed via two $24 \mathrm{~h}$ recall telephone interviews. The number of supplement users was lower according to the $24 \mathrm{~h}$ recalls compared with the number according to the computer-assisted telephone interview, as different time periods were assessed: two recall days and the previous 12 months, respectively.

\section{Discussion}

The present analysis provided insights into the heterogeneity among adult vitamin and mineral supplement users in Germany differentiated according to their motives for supplement use. The aims were to examine the motives for supplement use, to identify subgroups with similar motives, and to characterise these subgroups in terms of sociodemographic, lifestyle, health and dietary factors and supplement use. The most frequently reported motives in the overall group of supplement users were related to prevention and well-being. Three motive-based subgroups of supplement users were identified: a 'Prevention' subgroup, which was characterised by the motivation to prevent nutrient deficiencies; a 'Prevention and additional benefits' subgroup, which was characterised by the desire to prevent health problems and to improve well-being and performance; and a 'Treatment' subgroup, which was characterised by the intention to treat nutrient deficiencies or diseases.

The two prevention subgroups were similar in many respects; for example, members of both subgroups had a more favourable food choice than non-users. One noticeable difference between the two prevention subgroups was that those seeking additional benefits supplemented with a greater number of micronutrients. The 'Treatment' subgroup differed from the two prevention subgroups in that its members tended to be older and have a lower self-reported health status than non-users, and they supplemented with a smaller number of micronutrients than those in the other subgroups. Women were more likely to be supplement users than men, independent of their motives.

The most frequently reported motives for taking supplements and the characteristics of the overall group of supplement users reported in the present study are in close agreement with those reported by previous studies. These previous studies found that the most commonly reported motives were improving or maintaining health and well-being ${ }^{(7-9,34)}$. The majority of studies observed associations between supplement use and age, female gender, physical activity, having a special diet and making a healthy food choice ${ }^{(7,13,16,17,35,36)}$. Although most studies also observed that supplement users tended to have a higher level of education, a lower BMI and be less likely to smoke compared with non-users ${ }^{(7,13-15,37)}$, these 
associations were not observed in the present study. Regarding the relationship between health status and supplement use, contradictory results have been reported $^{(13,14,38,39)}$. These discrepancies may be due to differences in the study populations, the definitions of supplements and the assessment methods.

In extension to previous works, the present study demonstrates that supplement users do not form a homogeneous group. As described above, three subgroups of supplement users were differentiated by their motives, a 'Prevention' subgroup, a 'Prevention and additional benefits' subgroup and a 'Treatment' subgroup. To the best of our knowledge, this approach has not been used in previous studies. The characterisation of the motive-based subgroups showed that participants in the 'Prevention' and the 'Prevention and additional benefits' subgroups were very similar. They were more likely to have a special diet and to make a healthier food choice (demonstrated by their higher total HEI-NVS II scores) than non-users. They tended to have a higher dietary intake of several micronutrients compared with non-users, which indicates a higher consumption of nutrient-rich foods when taking into account the comparable amounts of energy intake between the prevention subgroups and non-users of supplements. Furthermore, they tended to spend more time on sports activities than non-users. Previous studies have shown that supplement users typically make a healthier food choice and have a healthier lifestyle than non-users ${ }^{(7,12,15,40)}$. The Swiss Food Panel (2010) also demonstrated that consuming a healthy diet was related to higher levels of health consciousness among supplement users ${ }^{(41)}$. These findings have led numerous researchers to support the inverse supplement hypothesis', which postulates that those who are the most likely use supplements are the least likely to need them ${ }^{(14,34,39,42)}$. The results from the present and previous studies indicate that many supplement users take a greater interest in nutritional issues than non-users and are generally more health conscious. It seems that supplement users are more likely to take an active role in their own health due to concerns about future health problems and that supplement use is just one effort among many to live a healthier lifestyle. The present results confirm the applicability of the inverse supplement hypothesis to the majority of supplement users.

Despite the many similarities between the two prevention subgroups, there were also some differences. Participants in the 'Prevention and additional benefits' subgroup supplemented with a greater number of vitamins and minerals than participants in the 'Prevention' subgroup. This is likely to be due to their preference for multivitamin-mineral products and their desire to achieve a wide range of objectives by taking supplements, as indicated by the fact that they tended to report a greater number of motives for taking supplements. Our results suggest that motives are associated with the types of supplements chosen and the range of micronutrients supplemented. Previous studies have also demonstrated that motives for taking supplements differ by the type of supplement used ${ }^{(34,43-45)}$.

The third subgroup of supplement users, the 'Treatment' subgroup, differed greatly from the two prevention subgroups. Their supplement use was associated with being older and having a lower self-reported health status. In a nationally representative survey of US adults (2007-2011), older individuals were found to be more likely to use supplements for specific health indications compared with younger individuals ${ }^{(34)}$. In contrast to those in the two prevention subgroups, those in the 'Treatment' subgroup did not spend more time on sports activities compared with non-users nor did they make a healthier food choice; instead, they tended to have a higher adjusted energy intake compared with non-users. Similarly, the Swiss Food Panel (2010) demonstrated that one-third of supplement users were categorised as having an unhealthy diet and that these users tended to have lower levels of health consciousness and poorer perceived health ${ }^{(41)}$. These findings indicate that there is a subgroup of supplement users that makes less effort to maintain a healthy lifestyle and that the inverse supplement hypothesis does not hold true for this subgroup. The present analysis also revealed that those in the 'Treatment' subgroup supplemented with a small number of micronutrients, which indicates a more targeted usage of supplements. This finding and those related to the lower self-reported health status and their reported motives support the assumption that individuals in the 'Treatment' subgroup supplement with specific micronutrients as a result of therapeutic indications (although no information on clinical diagnoses was gathered).

The present study clearly demonstrates that the characteristics of supplement users vary depending on their motives. Some of the characteristics observed in the overall group of supplement users were not confirmed for some of the motive-based subgroups. Other characteristics of the motive-based subgroups were masked when examining all the supplement users together and they only became apparent in the subgroup analyses. The study also revealed a link between motives and the types of supplements chosen as well as the numbers of vitamins and minerals supplemented.

The present study has several limitations. As the NEMONIT participants were recruited from the NVS II, there was a selection bias towards older, female and more highly educated participants ${ }^{(21)}$. As the results of exploratory cluster analyses are strongly dependent on the data structure and the samples on which the analyses are performed, small variations in the data may lead to different results. Consequently, further studies are needed to confirm the motive-based subgroups reported in the present study. Moreover, the cross-sectional nature of the study did not allow the causes behind the reported associations to be deduced. 
The study also has several major strengths. First, it explored the motives for supplement use in the whole German population rather than in a specific target group (e.g. athletes). Second, to our knowledge, it is the first study to identify distinct motive-based subgroups among supplement users. In the past, supplement users have mainly been differentiated by the types of supplements used and the reasons for taking supplements were not taken into account. Third, by characterising supplement users according to their motives, the study provides a far more differentiated picture than that provided by previous studies. A comparison of all the supplement users with the non-users would not have captured all the critical differences between the motivebased subgroups of supplement users.

\section{Conclusion}

The present study demonstrated that supplement users are heterogeneous in regard to their motives to take supplements, their sociodemographic, lifestyle, health and dietary characteristics, and their patterns of supplement use. The results indicate that a large proportion of supplement users in Germany take supplements for reasons related to prevention due to concerns about future health problems and it seems that supplement use is just one effort among others to maintain their health. The findings of their healthier lifestyle and food choice as well as their higher intake of several micronutrients from food alone (without considering supplements) support the inverse supplement hypothesis for those in the prevention subgroups. Taking supplements for additional benefits besides prevention is accompanied by the supplementation of a more extensive range of micronutrients. Only a small group of supplement users take supplements for the treatment of health problems. These supplement users tend to be older, have a lower health status and take supplements in a more targeted way. Such users may have underlying health indications for supplement use and they may therefore be more likely to benefit from supplementation than users who take supplements for reasons related to prevention. However, the actual need for nutritional supplementation among the subgroups remains to be examined. Future research should continue to investigate the heterogeneity among supplement users. Differentiated information on the motives, characteristics and usage patterns of supplement users can provide insight for the development of public health interventions against uncontrolled use of supplements in Germany.

\section{Acknowledgements}

Acknowledgements: The authors thank Dr Alexander Roth from the Department of Physiology and Biochemistry of Nutrition, Max Rubner-Institut (present address: Department of Child and Adolescent Psychiatry and
Psychotherapy, University of Zurich, Switzerland), for his statistical consulting. Financial support: NEMONIT was funded by the German Federal Ministry of Food and Agriculture, which had no role in the design, analysis or writing of this article. Conflict of interest: None. Authorship: A.F. developed the research question, analysed and interpreted the data, and drafted the manuscript. I.H. was involved in the data interpretation, manuscript preparation and critically reviewed the manuscript. T.H. was involved in the manuscript preparation and was responsible for the study design, data interpretation and final content. Ethics of buman subject participation: The survey was approved by the German Federal Data Protection Office and participants provided informed written consent after being informed in detail about the study and that participation was voluntary.

\section{Supplementary material}

To view supplementary material for this article, please visit https://doi.org/10.1017/S1368980017001021

\section{References}

1. Heuer T, Walter C, Krems C et al. (2012) Nährstoffzufuhr über Supplemente - Ergebnisse der Nationalen Verzehrsstudie II (Nutrient intake by supplements - results of the German National Nutrition Survey II). In Ernäbrungsbericht 2012 (The Nutrition Report 2012), pp. 86-97. Bonn: German Nutrition Society.

2. German Medicines Manufacturers' Association (editor) (2012) Der Arzneimittelmarkt in Deutschland in Zablen 2011 (Pharmaceutical Market in Germany in Figures 2011). Bonn: BAH Wissenschafts- und Wirtschaftsdienst.

3. Miller ER, 3rd, Pastor-Barriuso R, Dalal D et al. (2005) Meta-analysis: high-dosage vitamin E supplementation may increase all-cause mortality. Ann Intern Med 142, 37-46.

4. Satia JA, Littman A, Slatore CG et al. (2009) Long-term use of $\beta$-carotene, retinol, lycopene, and lutein supplements and lung cancer risk: results from the VITamins And Lifestyle (VITAL) study. Am J Epidemiol 169, 815-828.

5. Bjelakovic G, Nikolova D \& Gluud C (2013) Meta-regression analyses, meta-analyses, and trial sequential analyses of the effects of supplementation with $\beta$-carotene, vitamin A, and vitamin $\mathrm{E}$ singly or in different combinations on all-cause mortality: do we have evidence for lack of harm? PLoS One 8, e 74558 .

6. Braun H, Koehler K, Geyer H et al. (2009) Dietary supplement use among elite young German athletes. Int J Sport Nutr Exerc Metab 19, 97-109.

7. Pouchieu C, Andreeva VA, Peneau S et al. (2013) Sociodemographic, lifestyle and dietary correlates of dietary supplement use in a large sample of French adults: results from the NutriNet-Sante cohort study. Br J Nutr 110, 1480-1491.

8. Federal Institute for Risk Assessment (editor) (2013) Zielgruppengerechte Risikokommunikation zum Thema Nabrungsergänzungsmittel - Abschlussbericht (Target Group-Specific Risk Communication on Food Supplements Final Report). Berlin: BFR Wissenschaft.

9. Heinemann M, Willers J, Bitterlich N et al. (2015) Verwendung von Nahrungsergänzungsmitteln mit Vitaminen und Mineralstoffen - Ergebnisse einer deutschlandweiten Verbraucherbefragung (Use of nutritional supplements with vitamins and minerals - results of a Germany-wide 
consumer survey). J Verbraucherschutz Lebensmittelsicherh 10, 131-142

10. del Balzo V, Vitiello V, Germani A et al. (2014) A cross-sectional survey on dietary supplements consumption among Italian teenagers. PLoS One 9, e100508.

11. Li K, Kaaks R, Linseisen J et al. (2010) Consistency of vitamin and/or mineral supplement use and demographic, lifestyle and health-status predictors: findings from the European Prospective Investigation into Cancer and Nutrition (EPIC)-Heidelberg cohort. Br J Nutr 104, 1058-1064.

12. Kofoed CL, Christensen J, Dragsted LO et al. (2015) Determinants of dietary supplement use - healthy individuals use dietary supplements. Br J Nutr 113, 1993-2000.

13. Giammarioli S, Boniglia C, Carratu B et al. (2013) Use of food supplements and determinants of usage in a sample Italian adult population. Public Health Nutr 16, 1768-1781.

14. Rovira MA, Grau M, Castaner O et al. (2013) Dietary supplement use and health-related behaviors in a Mediterranean population. J Nutr Educ Behav 45, 386-391.

15. Reinert A, Rohrmann S, Becker N et al. (2007) Lifestyle and diet in people using dietary supplements: a German cohort study. Eur J Nutr 46, 165-173.

16. Marques-Vidal P, Pecoud A, Hayoz D et al. (2009) Prevalence and characteristics of vitamin or dietary supplement users in Lausanne, Switzerland: the CoLaus study. Eur J Clin Nutr 63, 273-281.

17. Beitz R, Mensink GBM, Hintzpeter B et al. (2004) Do users of dietary supplements differ from nonusers in their food consumption? Eur J Epidemiol 19, 335-341.

18. Touvier M, Niravong M, Volatier JL et al. (2009) Dietary patterns associated with vitamin/mineral supplement use and smoking among women of the E3N-EPIC cohort. Eur J Clin Nutr 63, 39-47.

19. Denison HJ, Jameson KA, Syddall HE et al. (2012) Patterns of dietary supplement use among older men and women in the UK: findings from the Hertfordshire Cohort Study. J Nutr Health Aging 16, 307-311.

20. Fitzmaurice J (2005) Incorporating consumers' motivations into the theory of reasoned action. Psychol Mark 22, 911-929.

21. Gose M, Krems C, Heuer T et al. (2016) Trends in food consumption and nutrient intake in Germany between 2006 and 2012: results of the German National Nutrition Monitoring (NEMONIT). Br J Nutr 115, 1498-1507.

22. Heuer T, Krems C, Moon K et al. (2015) Food consumption of adults in Germany: results of the German National Nutrition Survey II based on diet history interviews. $\mathrm{Br} \mathrm{J}$ Nutr 113, 1603-1614.

23. Slimani N, Deharveng G, Charrondiere RU et al. (1999) Structure of the standardized computerized 24-h diet recall interview used as reference method in the 22 centers participating in the EPIC project. European Prospective Investigation into Cancer and Nutrition. Comput Methods Programs Biomed 58, 251-266.

24. Slimani N, Ferrari P, Ocke M et al. (2000) Standardization of the 24-hour diet recall calibration method used in the European Prospective Investigation into Cancer and Nutrition (EPIC): general concepts and preliminary results. Eur J Clin Nutr 54, 900-917.

25. Wittig F \& Hoffmann I (2010) Ernährungsmuster von Bio-Käufern und Nicht-Bio-Käufern (Dietary patterns of buyers and non-buyers of organic food). In Auswertung der Daten der Nationalen Verzehrsstudie II (NVS II): eine integrierte verhaltens- und lebensbasierte Analyse des Bio-Konsums (Data Interpretation Based on the German National Nutrition Survey II (NVS II): An Integrative Analysis of Behavioural and Lifestyle-Related Factors for Organic Food Consumption), pp. 51-68 [I Hoffmann and A Spiller, editors]. Karlsruhe/Göttingen: Max Rubner-Institut/Georg-August-Universität Göttingen
(Department of Agricultural Economics and Rural Development); available at http://orgprints.org/18055/1/ 18055-08OE056_08OE069-MRI_uni-goettingen-hoffmann_ spiller-2010-verzehrsstudie.pdf

26. Oberritter H, Schäbethal K, von Ruesten A et al. (2013) The DGE-Nutrition Circle - representation and fundamentals of the food-based recommendations of the German Nutrition Society. Ernaehrungs Umschau Int 60, 24-29.

27. German Nutrition Society, Austrian Nutrition Society \& Swiss Nutrition Society (editors) (2015) Referenzwerte für die Nährstoffzufubr (Reference Values for Nutrient Intake), 2nd ed. Bonn: German Nutrition Society.

28. Hartmann BM, Heuer T \& Hoffmann I (2015) The German Nutrient Database: effect of different versions on the calculated energy and nutrient intake of the German population. J Food Compost Anal 42, 26-29.

29. Kubinger KD (2003) On artificial results due to using factor analysis for dichotomous variables. Psychol Sci 45, 106-110.

30. DiStefano C, Zhu M \& Mindrila D (2009) Understanding and using factor scores: considerations for the applied researcher. Pract Assess Res Eval 14, issue 20, http:// pareonline.net/pdf/v14n20.pdf

31. Ward JH (1963) Hierarchical grouping to optimize an objective function. J Am Stat Assoc 58, 236-244.

32. Caliński T \& Harabasz J (1974) A dendrite method for cluster analysis. Commun Stat 3, 1-27.

33. Milligan GW \& Cooper MC (1987) Methodology review: clustering methods. Appl Psychol Meas 11, 329-354.

34. Bailey RL, Gahche JJ, Miller PE et al. (2013) Why US adults use dietary supplements. JAMA Intern Med 173, 355-361.

35. McNaughton SA, Mishra GD, Paul AA et al. (2005) Supplement use is associated with health status and health-related behaviors in the 1946 British birth cohort. J Nutr $\mathbf{1 3 5}$, $1782-1789$.

36. Skeie G, Braaten T, Hjartaker A et al. (2009) Use of dietary supplements in the European Prospective Investigation into Cancer and Nutrition calibration study. Eur J Clin Nutr $\mathbf{6 3}$, Suppl. 4, S226-S238.

37. Touvier M, Kesse E, Volatier JL et al. (2006) Dietary and cancer-related behaviors of vitamin/mineral dietary supplement users in a large cohort of French women. EurJ Nutr 45, 205-214.

38. Knudsen VK, Rasmussen LB, Haraldsdóttir J et al. (2002) Use of dietary supplements in Denmark is associated with health and former smoking. Public Health Nutr 5, 463-468.

39. Harrison RA, Holt D, Pattison DJ et al. (2004) Are those in need taking dietary supplements? A survey of 21923 adults. Br J Nutr 91, 617-623.

40. Mensink GBM \& Ströbel A (1999) Einnahme von Nahrungsergänzungspräparaten und Ernährungsverhalten (Intake of dietary supplements and nutritional behaviour). Gesundheitswesen 61, Suppl. 2, S132-S137.

41. van der Horst K \& Siegrist M (2011) Vitamin and mineral supplement users. Do they have healthy or unhealthy dietary behaviours? Appetite. 57, 758-764.

42. Kirk S, Woodhouse A, Conner M et al. (1998) Beliefs, attitudes and behaviour in relation to supplement use in the UK Women's Cohort Study (UKWCS). Proc Nutr Soc 57, 54A.

43. Neuhouser ML, Patterson RE \& Levy L (1999) Motivations for using vitamin and mineral supplements. J Am Diet Assoc 99, 851-854.

44. Brownie S \& Rolfe M (2005) Supplement utilisation patterns of older Australians: results from a randomly selected national sample. Nutr Diet 62, 89-94.

45. Barnes K, Ball L, Desbrow B et al. (2016) Consumption and reasons for use of dietary supplements in an Australian university population. Nutrition 32, 524-530. 